\title{
Possibility of hydrogen supply by shared residential fuel cell systems for fuel cell vehicles
}

\author{
Yusuke Ono, Takahide Haneda*, Takashi Ikegami, and Atsushi Akisawa \\ Tokyo University of Agriculture and Technology, 2-24-16, Nakacho Koganei, Tokyo, Japan
}

Received: 15 January 2017 / Received in final form: 24 July 2017 / Accepted: 27 July 2017

\begin{abstract}
Residential polymer electrolyte fuel cells cogeneration systems (residential PEFC systems) produce hydrogen from city gas by internal gas-reformer, and generate electricity, the hot water at the same time. From the viewpoint of the operation, it is known that residential PEFC systems do not continuously work but stop for long time, because the systems generate enough hot water for short operation time. In other words, currently residential PEFC systems are dominated by the amount of hot water demand. This study focuses on the idle time of residential PEFC systems. Since their gas-reformers are free, the systems have potential to produce hydrogen during the partial load operations. The authors expect that residential PEFC systems can take a role to supply hydrogen for fuel cell vehicles (FCVs) before hydrogen fueling stations are distributed enough. From this perspective, the objective of this study is to evaluate the hydrogen production potential of residential PEFC systems. A residential PEFC system was modeled by the mixed integer linear programming to optimize the operation including hydrogen supply for FCV. The objective function represents annual system cost to be minimized with the constraints of energy balance. It should be noted that the partial load characteristics of the gas-reformer and the fuel cell stack are taken into account to derive the optimal operation. The model was employed to estimate the possible amount of hydrogen supply by a residential PEFC system. The results indicated that the system could satisfy at least hydrogen demand for transportation of $8000 \mathrm{~km}$ which is as far as the average annual mileage of a passenger car in Japan. Furthermore, hydrogen production by sharing a residential PEFC system with two households is more effective to reduce primary energy consumption with hydrogen supply for FCV than the case of introducing PEFC in each household.
\end{abstract}

\section{Introduction}

Fuel cell vehicles (FCVs) are one of the solutions to reduce carbon dioxide $\left(\mathrm{CO}_{2}\right)$ emissions. They utilize fuel cells as an energy resource to generate electricity via an electrochemical reaction in which hydrogen acts as the fuel and oxygen or air as the oxidant. The FCVs, being more efficient than the current internal combustion vehicles owing to the use of a direct energy conversion process [1], are considered the most promising technology next to battery and plug-in hybrid vehicles. A Japanese motor corporation has been selling commercial FCVs since December 2014, and other companies are prepared to enter the FCV market as well. The increased number of hydrogen fueling stations is essential for operating FCVs; however, there were only 81 working hydrogen fueling stations distributed across Japan in 2016 [2]. Therefore, it has become increasingly necessary to grow the network of hydrogen fueling stations.

\footnotetext{
* e-mail: haneda@tokyo-gas.co.jp
}

Residential polymer electrolyte fuel cell (PEFC) cogeneration systems produce hydrogen from city gas by an internal steam reformer and generate power and hot water. It was first launched in 2009 and more than 200000 units have been installed in Japan as of 2017 [3]. However, the PEFC systems are inoperative most of the time during the summer and late at night when the hot water demand is low, since the operation follows the hot water demand of residential houses [4].

In this research, the authors focus on the hydrogen production function of the PEFC systems and suggest an energy system that produces hydrogen as fuel for FCVs using the hydrogen production capacity during nonoperation and partial-load operation times of PEFC systems. This energy system is expected to replace the hydrogen fueling station until the full extension of it. The aim of this study is to evaluate hydrogen production of the PEFC systems based on the energy demand of residential houses equipped with PEFC systems. Using this model, samples of 24 households were analyzed to estimate the range of hydrogen production by PEFC systems. Furthermore, the possibility of hydrogen production by 


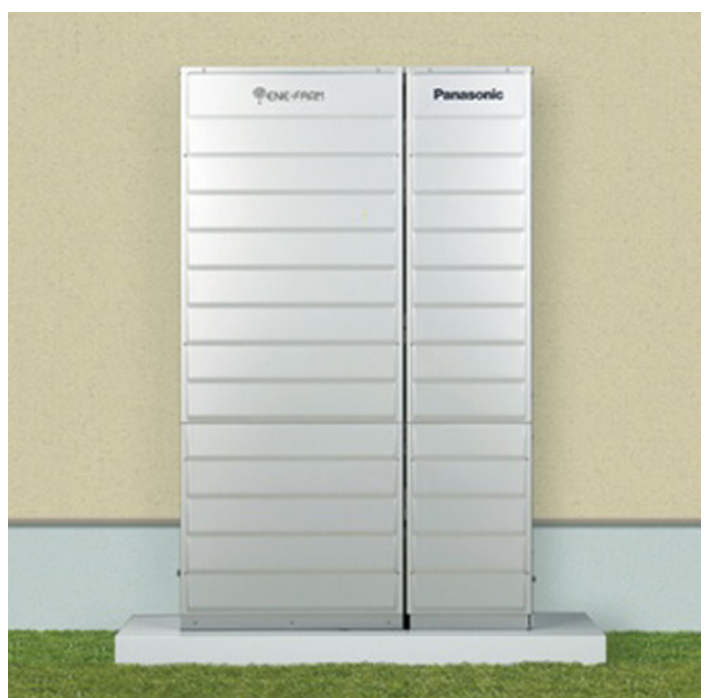

Fig. 1. Photo of a PEFC system.

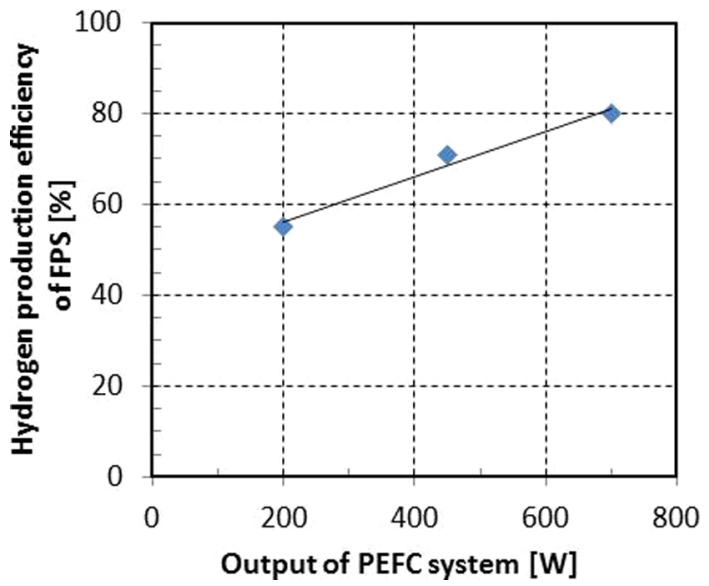

Fig. 2. Partial load efficiency of the FPS.

sharing a PEFC system between two households is discussed to evaluate the effectiveness of such a system in reducing primary energy consumption (Fig. 1).

\section{Methodology}

\subsection{PEFC system with hydrogen production for FCV}

The proposed system targets the residential houses with equipped PEFC systems. The PEFC system with hydrogen production (PEFC with $\mathrm{H}_{2}$ system) produces hydrogen for FCVs and stores it in a tank satisfying power and the hot water demand of the residential houses. The PEFC with $\mathrm{H}_{2}$ system is composed of a fuel processor system (FPS) for hydrogen production, a fuel cell stack, a storage tank for hot water, a storage tank for hydrogen, and a gas boiler for additional hot water production. Fuel cell stack can generate power ranging from $200 \mathrm{~W}$ to $700 \mathrm{~W}$ [5]. Moreover, it is assumed that the FPS and the fuel cell stack can be operated separately, that is, hydrogen as fuel for FCV can be produced using the hydrogen production capacity during non-power and partial-load power generation periods.

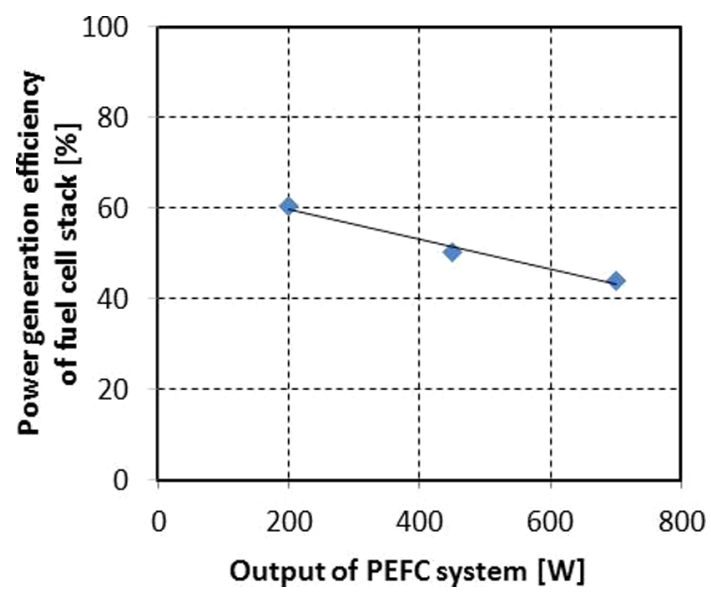

Fig. 3. Partial load efficiency of the fuel cell stack.

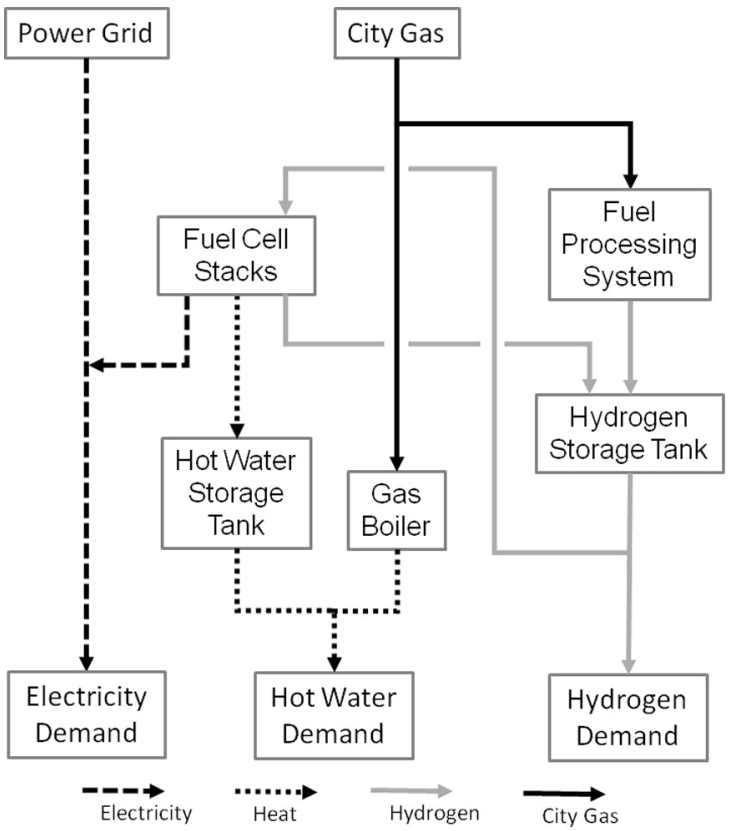

Fig. 4. Schematic diagram of energy flows in the proposed PEFC with $\mathrm{H}_{2}$ system.

In the conventional PEFC systems, the FPS and the fuel cell stack operate at the same rate load. However, the FPS and the fuel cell stack have partial load efficiency characteristics as shown in Figure 2 [6] and Figure 3 [7]. Therefore, if the FPS is operated at the maximum output and the fuel cell stack is operated at the minimum output, a more efficient operation becomes possible. In the conventional PEFC systems, hydrogen is produced more than it is used in the fuel cell stack: $20 \%$ of hydrogen produced by the FPS is burned as a fuel in the FPS [8]. In the proposed system, the surplus hydrogen is used to supply to FCV and city gas with energy equivalent to hydrogen is introduced into the FPS.

\subsection{Mathematical model for the energy system for residential houses}

Figure 4 shows the energy flow diagram for the mathematical model which targets the residential houses equipped with the PEFC with $\mathrm{H}_{2}$ system. Electric power is 
supplied by both the power grid and a fuel cell stack. Hot water is supplied by both a fuel cell stack and a gas boiler attached in the PEFC systems. Hydrogen as fuel for FCV is produced during non-power and partial-load power periods, stored in a hydrogen storage tank, and used to supply FCV in the morning. The model takes into account the partial load efficiency of the FPS and the fuel cell stack.

\subsection{Simulation conditions}

Energy demands used in the model are from the measured values of 24 samples of detached houses in Tokyo and Kanagawa. Regarding power and hot water demand, hourly data of the monthly representative days were used. Furthermore, hydrogen demand for FCV was assumed to range from 0 (not possessing FCV) to $24000 \mathrm{~km}$ a year. The average annual mileage of a passenger car in Japan is approximately $8000 \mathrm{~km}$. The amount of hydrogen needed to meet the demands of the household was calculated based on a specification table of commercial FCVs [9]. The model assumes that the daily hydrogen demand is constant. The objective function was set to minimize the total cost of the energy system including the fixed cost and the fuel cost as defined in equation (1), where $C, C_{i}$ and $C_{\text {run }}$ denote total annual cost, fixed cost and fuel cost in Japanese yen, respectively.

$$
C=C_{i}+C_{\text {run }} \rightarrow \text { Min. }
$$

\section{Results}

\subsection{Sensitivity analysis of the maximum hydrogen supply for FCV}

In order to estimate the amount of maximum hydrogen supply to FCV for 24 residential houses, the sensitivity analysis was conducted by changing hydrogen demand. Figure 5 shows the annual operating rate of the fuel cell stack and the FPS of a sample for different annual hydrogen demand. Annual operating rate is defined in equation (2).

\section{[Annual operation rate] \\ $=($ total annual output $) /($ rated output $\times 8760)$.}

The operation rate of the fuel cell stack is approximately $75 \%$ when hydrogen for FCV is not produced (conventional PEFC system operation method), The operating rate was almost constant for annual hydrogen production of up to $12000 \mathrm{~km}\left(\mathrm{H}_{2}: 1560 \mathrm{Nm}^{3}\right)$ and decreased if more hydrogen is produced. This indicates that hydrogen used for power generation in the fuel cell stack is considered insufficient and its function in the cogeneration system is impaired. Therefore, the household is able to produce hydrogen for up to $12000 \mathrm{~km}$ using the cogeneration system without any damage on the PEFC system operation.

The sensitivity analysis was then conducted for all 24 houses and the distribution of the maximum hydrogen production is shown in Figure 6. In all households, it was possible to produce hydrogen for $8000-20000 \mathrm{~km}$ of use while maintaining the cogeneration function. Considering

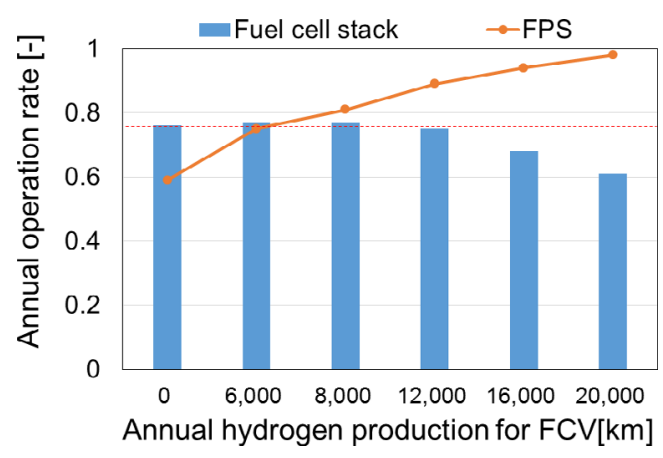

Fig. 5. Analysis of maximum hydrogen supply.

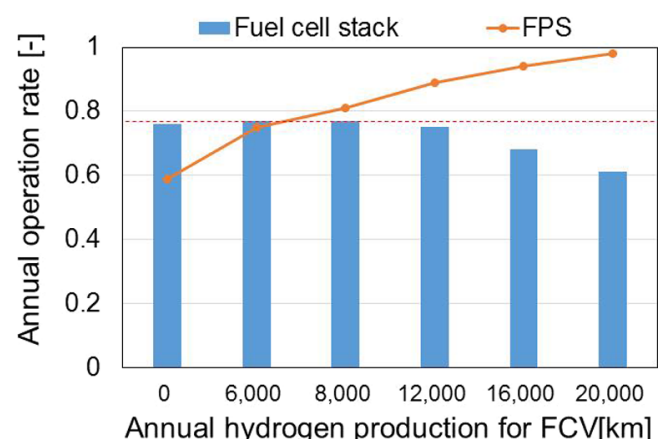

Fig. 6. Distribution of maximum hydrogen production.

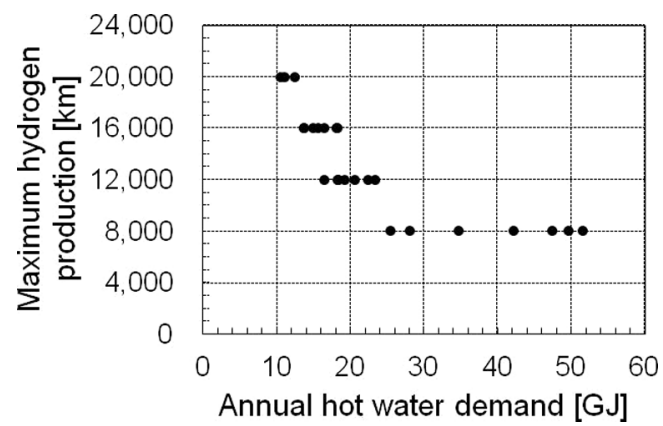

Fig. 7. Relationship between hydrogen production and hot water demand.

that the annual average mileage for a passenger car is about $8000 \mathrm{~km}$, the result suggests that at least one FCV can be fueled by the PEFC system installed at a household.

Furthermore, the relationship between hydrogen production and annual hot water demand is shown in Figure 7 . The higher the hot water demand, the higher the fuel cell operation rate, the more frequent hydrogen usage for power generation, and the lower the amount of hydrogen supplied to FCV. On the other hand, the maximum hydrogen production is larger for the houses with less hot water demand.

As the figure demonstrates, it was confirmed that the maximum hydrogen production changes $20000-16000 \mathrm{~km}$ around 12 GJ and changes $12000-8000 \mathrm{~km}$ at around 25 GJ. In contrast, the clear boundary of the hot water demand is not observed between the maximum hydrogen production of 


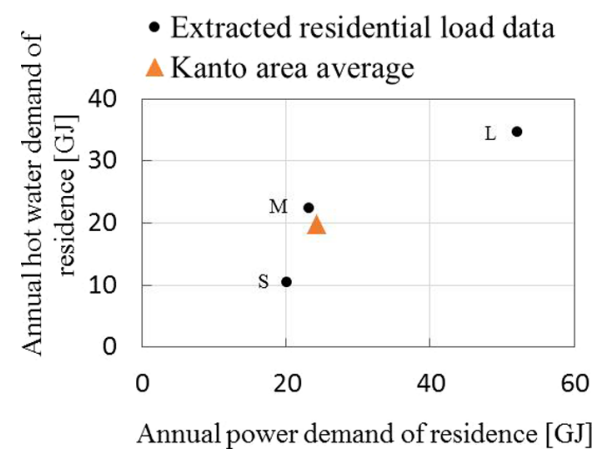

Fig. 8. Distribution of extracted residential load data.

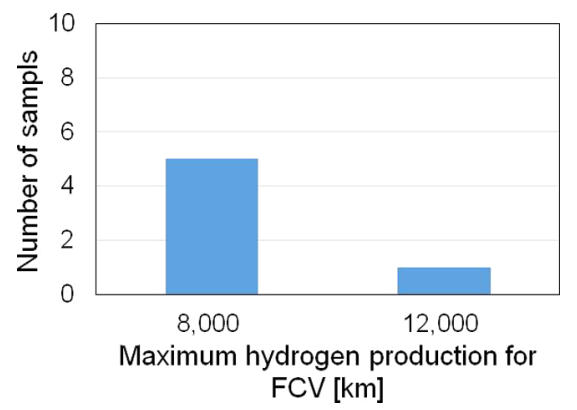

Fig. 9. Distribution of maximum hydrogen production (two households).

$12000 \mathrm{~km}$ and $16000 \mathrm{~km}$. However, the maximum hydrogen production will be estimated from the annual hot water demand of the households using this relationship.

\subsection{Sharing PEFC system between two households}

The authors propose sharing a PEFC with two households. The sharing is expected to reduce the installation cost for one household, which will be effective to diffuse PEFC systems into the market. It is examined how the sharing systems with hydrogen production work in this study. In order to determine the maximum hydrogen production for shared $\mathrm{PEFC}$ with $\mathrm{H}_{2}$ system by two households, three data points were selected from 24 demands, and six demands were created by combining these data points. The relationship between the annual power demand and annual hot water demand is shown in Figure 8. The data point which is close to the average demand of Kanto area including Tokyo is $\mathrm{M} ; \mathrm{S}$ is the data point with low values of hot water demand and power demand; and L has high values of hot water demand and power demand.

Sensitivity analysis was carried out in order to examine the maximum hydrogen production. As shown in Figure 9, all households can produce hydrogen for at least $8000 \mathrm{~km}$ of travel $\left(\mathrm{H}_{2}: 1040 \mathrm{~N} \mathrm{~m}^{3}\right)$ with cogeneration. As a result, the amount of hydrogen which is equivalent to fuel used for driving $8000 \mathrm{~km}$ can be supplied with the surplus hydrogen by the shared PEFC system.

\subsection{Effect of primary energy reduction}

In this section, three cases are investigated to derive the effect in consumption of primary energy (PE). First case is for the PEFC with $\mathrm{H}_{2}$ system and FCV ownership, the

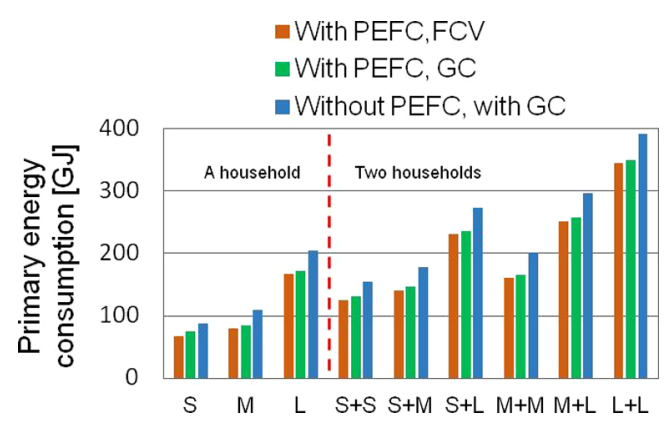

Fig. 10. Primary energy consumption.

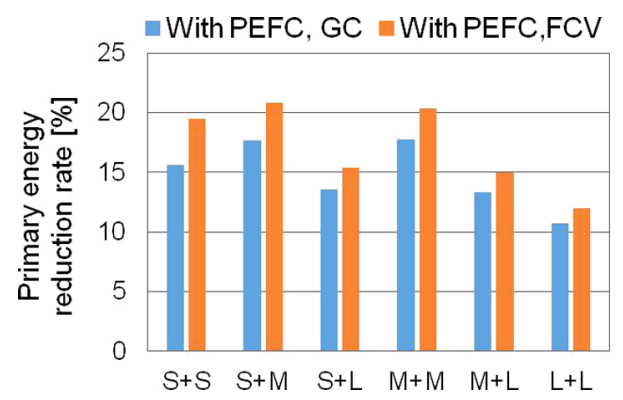

Fig. 11. PE reduction rate based on the case without the PEFC system and with GV.

second one is for the conventional PEFC system and gasoline vehicle (GV) ownership, and the last one is for GV only. It is assumed that both GV and FCV are driven $8000 \mathrm{~km}$ per year. In addition, authors used the value of $34.6 \mathrm{MJ} / \mathrm{L}$ as the primary energy equivalent value of gasoline. Figure 10 shows the $\mathrm{PE}$ consumption in each case. S, M, L represents the households from Figure 8, and the other points in the $x$-axis represent the consumption of two-household combinations. For any demand pattern, the consumption of primary energy can be reduced when the PEFC system is introduced. The consumption can be further reduced by driving an FCV rather than a GV.

The change in the $\mathrm{PE}$ reduction rate for two households with different hot water and power demand is shown in Figure 11 for the first and second cases. The maximum PE reduction rate was about $20 \%$ and the reduction rate of the first case (the PEFC system with FCV) was higher than the case with the PEFC system and GV for all household types. As energy demand increase $(\mathrm{M}+\mathrm{L}$ and $\mathrm{L}+\mathrm{L})$, the primary energy consumption increase and the reduction rate decrease even when the PEFC system operates at the maximum output.

To understand the effect of one unit of the PEFC system, it is meaningful to compare the $\mathrm{PE}$ reduction rate per the PEFC system between the case of the PEFC system in each residence and FCV ownership and the case of the shared PEFC system and FCV ownership (Fig. 12). This is based on the case of owning GV without the PEFC system. When the energy demand is small, the cogeneration is more active in the sharing case and the $\mathrm{PE}$ reduction rate is larger. In contrast, as energy demand get higher, the difference between the $\mathrm{PE}$ reduction rates of both cases get smaller because energy demand that cannot be covered by cogeneration increases in the shared case. 


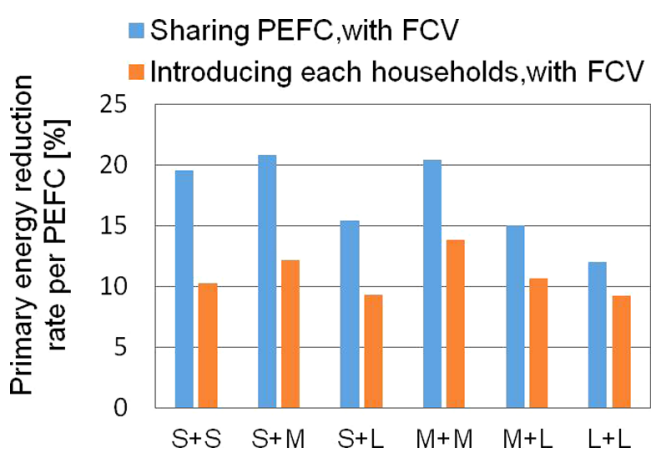

Fig. 12. Comparison of the case of sharing and introducing each other (based on the case without the PEFC system and with GV).

Figure 13 shows the PE reduction rate per the PEFC system based on the case with the PEFC system and GV. The results show that the consumption can be reduced by $9 \%$ at most from the case with GV because the fuel cell stack and the FPS can operate more efficiently. When the total energy demand is small, at the non-shared case, the load per the PEFC system is too small to operate as cogeneration. For this reason, the operation rate of each cogeneration unit and thus the reduction rate are low. On the other hand, when energy demand is large, at the shared case, energy demand that cannot be covered by the PEFC system increase, so the PE reduction rate significantly decrease. These results show that the sharing PEFC system between houses with low or average energy demand greatly contributes to the $\mathrm{PE}$ reduction. It should be noted that this analysis does not take into account the PE consumption necessary to store hydrogen to a storage tank, to purify and compress hydrogen with the maximum pressure of $70 \mathrm{MPa}$, which is essential for hydrogen supply for FCV. Therefore it should be the subject of future work.

\section{Conclusions}

This study investigated the possibility of producing hydrogen for FCVs by PEFC systems which are installed for residential cogeneration. PEFC systems have the capability to generate hydrogen when they do not work at full capacity. The performance of the PEFC system was analyzed based on the observed energy demands of various households. It was found that one unit of the PEFC system could supply hydrogen to run an FCV for at least $8000 \mathrm{~km}$ which is equivalent to the average annual trip distance in Japan.

Sharing one unit of the PEFC system between two households was examined because it can reduce the total capacity of the PEFC system, which decreases the installation cost. According to the simulations, the sharing system is expected to reduce the primary energy consumption by $10-20 \%$ compared with the conventional case. In terms of the reduction rate, one PEFC system of the sharing system attains a better performance than the case with separated PEFC systems. The sharing system is also advantageous in replacing gasoline fuel with hydro-

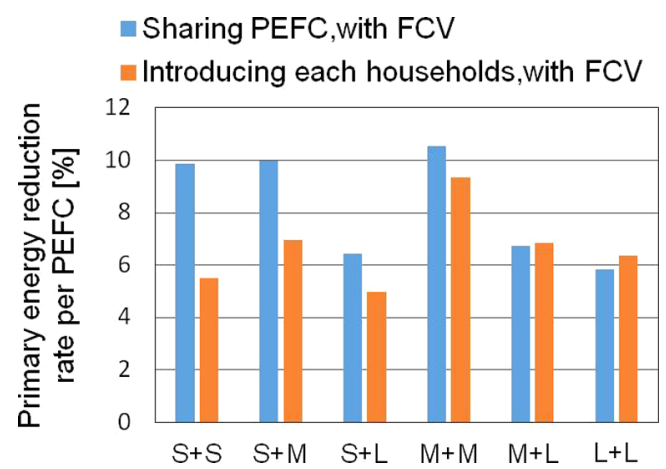

Fig. 13. Comparison of the case of sharing and introducing each other (based on the case with the PEFC system and GV).

gen when the energy demand is relatively small. Because the energy for compressing hydrogen to charge FCVs is not considered in this study, further investigation is required on this topic.

Consequently, the results suggests that residential PEFC systems can be used for supplying hydrogen for FCVs and support the widespread use of FCVs while hydrogen stations are still being built to meet the demands of the growing FCV market.

\section{References}

1. C. Stefano, M. Giampaolo, I.F. de la Garcia, Energy analysis of electric vehicles using batteries or fuel cells through well to wheel driving cycle simulations, J. Power Sources 186, 464 (2009)

2. Fuel Cell Commercialization Conference on Japan, Information of Commercial Hydrogen Station (2017), Available from http://fccj.jp/hystation/index.html \#hystop [in Japanese]

3. Enefarm Partners, For Residential Fuel Cells "ENE-FARM" Cumulative 150,000 Breakthrough, Press Release on December 12 (2015), Available from: http://www.gas.or.jp/news release/2017ef20.pdf [in Japanese]

4. K. Kobayashi, About newest residential fuel cell cogeneration system 'Enefarm', Hydrogen Energy Syst. 36, 51 (2011) [in Japanese]

5. Tokyo Gas Co., Ltd., Specification of Enefarm (2016), Available from http://www.tokyo-gas.co.jp/home.tokyogas.co.jp/enefarm_special/enefarm/specific.html [in Japanese]

6. H. Aki, S. Yamamoto, J. Kondoh, A. Murata, I. Ishii, T. Maeda, Analyses on cost reduction and $\mathrm{CO}_{2}$ mitigation by penetration of fuel cells to residential houses, Trans. Inst. Electr. Eng. Jpn. B 124, 431 (2004) [in Japanese]

7. T. Wakui, N. Wada, R. Yokoyama, Energy-saving effect of a residential polymer electrolyte fuel cell cogeneration system combined with a plug-in hybrid electric vehicle, Energy Convers. Manag. 77, 40 (2014)

8. Y. Mugikura, Electrochemical investigation of fuel cell performance, Hydrogen Energy Syst. Soc. Jpn. 35, 50 (2010)

9. Toyota Motor Corporation, Specification of Mirai (2015), Available from http://toyota.jp/pages/contents/mirai/ 001 _p_001/pdf/spec/mirai_spec_201508.pdf [in Japanese] 